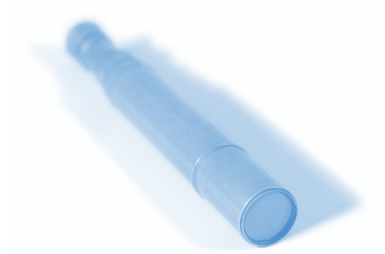

Jonathan Chippindall

Access and Community Engagement

University of Leeds

Leeds

LS2 9JT

jchippindall@gmail.com

\section{Making physics a smash hit: The use of popular culture in science outreach}

\begin{abstract}
This paper examines the incorporation of popular culture into science outreach activities as a means of improving the engagement level of secondary school pupils. Two activities make up the case studies discussed within this paper: 'The Science of Sound' and 'The Music Festival'. Both case studies utilise the creation and consumption of popular music as a means to; convey physics principles; promote the continued study of physics and raise awareness of the broad range of careers that physics graduates can pursue. Consultation with a range of stakeholders involved in the development, delivery, and participation in the case study activities has been undertaken. This includes a focus group with participating Year 10 students and interviews with secondary school teachers and outreach coordinators. The purpose of this paper is to explore the advantages, disadvantages, and challenges in using popular culture to stimulate engagement in this way, and to share best practise to aid the effective delivery of similar initiatives.

\section{Introduction}

The importance of developing a workforce which is highly skilled in Science, Technology, Engineering and Maths (STEM) to the future prosperity of the UK economy was brought into focus in 2007 by Lord Sainsbury's review of the Government's Science and Innovation Policy ${ }^{1}$. More recently, research by the Confederation of British Industry has indicated that, despite current economic conditions, the demand for STEM graduates remains high: with nine out of ten firms employing STEM skilled people and four out of ten firms preferring STEM degrees to any other subject. As such, remuneration for STEM graduates remains relatively substantial, with an average starting salary of $£ 22,000$ for a graduate scientist ${ }^{2}$. Yet, against this backdrop of opportunity and reward, the number of students pursing STEM subjects within Higher Education remains low, with only $13 \%$ of university students studying the core STEM disciplines of physics, biology, chemistry, maths, engineering and technology ${ }^{3}$.
\end{abstract}

This paper considers two science outreach activities delivered within secondary schools in an attempt to increase participation levels in physics within Higher Education. More specifically, this paper explores the use of popular culture in such activities - explicitly the creation and/or consumption of music - as a vehicle to; convey physics principles; promote the study of physics, and; raise awareness of the broad range of careers that physics graduates can pursue. The aim of this paper is to investigate whether incorporating popular culture into science outreach helps to increase the engagement level of participating pupils and also to highlight potential pitfalls in this approach.

In the following section of this paper a brief overview of the two outreach activities is provided. This is followed by a discussion section which has been structured to communicate the opinions expressed by a range of stakeholders. Research for this paper has included focus groups with secondary school pupils and interviews with secondary school teachers and the outreach coordinators. The final section of this paper highlights the main conclusions of this research and presents best practise to aid the effective and efficient delivery of similar initiatives.

\section{Case studies}

Two outreach activities make up the case studies discussed in this paper: 'The Science of Sound' and 'The Music Festival', a summary of each activity is presented in figures one and two respectively. 


\begin{tabular}{|c|c|}
\hline The Science of Sound & \\
\hline Duration & Two hour workshop \\
\hline Capacity & Up to 20 pupils \\
\hline Year group & 10 and 11 \\
\hline Description & $\begin{array}{l}\text { 'The Science of Sound' focuses on the link between } \\
\text { physics. Pupils alternate between producing their ow } \\
\text { available music production software) and learning ab } \\
\text { improve their compositions, such as bit-depth and sa } \\
\text { recording, or the artificial addition of reverberations } d\end{array}$ \\
\hline Academic content & $\begin{array}{ll}\text { - } & \text { Creation of sound } \\
\text { - } & \text { Parameters of sound waves } \\
\text { - } & \text { Propagation of sound waves } \\
\text { - } & \text { Analogue and digital signals } \\
\text { - } & \text { Sampling: Analogue to digital single conversion }\end{array}$ \\
\hline
\end{tabular}

Figure 1: Summary of 'The Science of Sound'

\section{Discussion}

\section{Secondary school pupils}

Many of the pupils that participated in the focus groups, or completed activity evaluation forms, expressed that the cultural focus of the outreach activities featured in this paper did indeed make the activities 'more interesting' since the physics was made applicable to their own interests. Certainly many of the pupils accurately recalled the physics concepts conveyed during the outreach work, despite six months having passed since the events. It is worth noting that in defining their level of 'interest', several pupils made reference to the minimal provision of practical sessions in their school based physics lessons. This is important, since it has been argued, most recently by the Children, Schools and Families Commitee ${ }^{4}$, that education and in particular science education, may have suffered at the hands of an overly-prescriptive National Curriculum which has reduced teachers' capacity and confidence in delivering enriching experimental sessions.

Many pupils felt the cultural focus of the outreach activities had widened their perception of physics based careers, and were surprised to learn that a career in physics was not necessarily constrained to a laboratory. Indeed many pupils were interested to hear that an understanding of physics was important in jobs which they perceived to be quite distant from

\section{The Music Festival}

Duration

Capacity

Year group

Description

Academic content

\section{One full school day 12 teams of six 10}

'The Music Festival' revolves around the physics in music festival production. Pupils adopt a specialist role within teams and develop a proposal for running a music festival. Team roles include Project Manager, Sound Engineer, Lighting Engineer, Health and Safety Manager, Electrical Design Engineer and Construction Design Engineer.

- Properties of sound

- Properties of light

- Electrical power

- Optical power

- Digital control 
science: such as music production or the running of music festivals. The lack of informative STEM careers advice for secondary school pupils has previously been cited as a potential contributing factor to low STEM numbers within Higher Education ${ }^{5}$. Certainly anecdotal evidence from the University of Leeds 'Reach for Excellence' programme indicates that the majority of students studying the sciences at A-Level tend to pursue subjects which they perceive lead to clearer defined career opportunities: medicine and dentistry being the preferred option ${ }^{6}$. Hence, it appears of considerable value that in addition to conveying academic concepts, science outreach initiatives continue to educate pupils about the broad range of career opportunities available to STEM graduates.

On a negative note, a few pupils expressed scepticism over how effective the outreach activities had been at connecting with their popular culture. This was particularly applicable for 'The Science of Sound', in which pupils use short clips of music (termed audio loops) to construct their musical compositions. Whilst every effort was made to cater for the wide range of musical tastes amongst young people, on occasion pupils were unhappy with the genres of audio loops available, and this subsequently acted as a barrier in engaging the pupils in the workshop content. This highlighted the importance of consulting, where possible, with secondary school pupils during the development stage of activities, since 'missing the mark' with cultural references will hinder the effectiveness of an activity as opposed to aiding it.

Finally, it was evident from observing the activities, that whilst the majority of pupils appreciated the association between science and popular culture, a minority of pupils were content to let the cultural element of the activities act as a distraction from the science. It was therefore important to emphasis the interdependence between the popular culture and the science concepts - thus making the science unavoidable. A good example of such interdependence is the use of musical effects, such as reverb, within 'The Science of Sound'. Reverb units are used to artificially add reverberations to music during production and can influence the style of the music considerably. However, to understand the controls on a reverberation unit requires a reasonable level of knowledge of reverberate fields, which offers ample scope to explore a variety of physics concepts.

\section{Secondary School Teachers and Outreach Coordinators} Of those teachers that gave their opinions to contribute to this research, the vast majority expressed a strong support for the delivery of science outreach within their schools. It was voiced that the school based provision of equivalent initiatives was often not feasible in terms of the time required to develop such activities or the availability of resources. Hence teachers were pleased to be enriching their learners' education by means of help from external organisations. Furthermore some teachers remarked that their own knowledge of physics careers had benefit from overhearing the content of the outreach activities, this is not entirely surprising given $75 \%$ of English schools do not have any specialist physics teachers ${ }^{7}$.

On the topic of using popular culture within science outreach; on the whole teachers and outreach coordinators felt that pupils did recognise, and appreciated, any attempt to relate material to the pupils' personnel interests. Indeed making concepts and material applicable to learners is good teaching practise, and consequently teachers did believe that popular culture could 'be used effectively to capture students' interest and imagination'. In addition, several teachers pointed out that highlighting the link between subjects, including Science, Mathematics, ICT and Music, assists cross-curricular learning and thus enriches the teaching efforts for a range of school departments.

The main area of concern for a few teachers was ensuring that a suitable balance was struck between science and popular culture: to ensure the 'science wasn't lost' or the 'depth of scientific understanding compromised'. However, this was not a universal opinion held by all teachers and in direct contrast it was also highlighted that the activities' academic depth was 'not a primary consideration' since the activities would be used as 'an extension and to generate interest' as opposed to a primary teaching tool. Outreach coordinators tended to support the latter of these opinions, highlighting that the most successful activities are those which cover different material to that in class and, above all, are fun to participate in.

Finally, several teachers echoed the sentiments of pupils in that they raised concern about using pupils' popular culture without risk of 'missing the mark' and thus actually creating a barrier to learning with 'out of date' cultural references.

\section{Observations}

- It can be concluded from this paper that incorporating popular culture into science outreach activities can be advantageous in terms of increasing pupils' engagement.

- It is apparent from the opinions of the pupils who participated in this research that integrating popular culture into science outreach can be of value in countering misconceptions pupils' hold of STEM careers. 
Specifically, many pupils were surprised to learn of the broad range of careers available to STEM graduates and that such careers were not constrained to a laboratory setting.

- This research has indicated that care must be taken when employing popular culture within science outreach, since 'missing the mark' with cultural reference can hinder engagement as opposed to promoting it.

- When developing outreach activities, effort should be made to 'design in' interdependence between the scientific concepts and elements of popular culture. Furthermore this interdependence should be emphasised during delivery of the activity; thus making an understanding of the scientific concepts integral to fulfilling the wider aims of the activity.

- Adequate and appropriate consultation during the activity development stage provides exposure to the requirements of teachers and affords a valuable opportunity to ensure the uses of cultural references are appropriate to the target cohort of pupils. In addition, a willingness to learn from feedback by iteratively refining activities and updating cultural references will ensure such initiatives are continually improved.

\section{References}

1. Lord Sainsbury of Turville, (2007) The Race to the Top: A review of Government's Science and Innovation Policy.

2. Confederation of British Industry, (2009) Emerging stronger: the value of education and skills in turbulent times.

3. Higher Education Statistics Agency data for 2006/7.

4. House of Commons Children, Schools and Families Committee, (2009) National Curriculum, Forth Report of Session 2008-09, Volume 1.

5. The need for an improvement in the quality and provision of STEM careers advice was brought into focus by the Minister for Lifelong Learning, Further and Higher Education, Bill Rammell, speaking at an Institute for Public Policy Research conference in May 2007.

6. STEM subjects accounted for $48 \%$ of the qualifications being taken by the cohort of students on the University of Leeds 'Reach for Excellence' program. However, of these students only $9 \%$ expressed an interest in studying a STEM subject within Higher Education, as opposed to $27 \%$ whom expressed an interest in Medicine or Dentistry.

7. Smithers, A. Robinson, P. (2008) Physics in schools: Supply and Retention of Teachers, Buckingham: Carmichael Press.

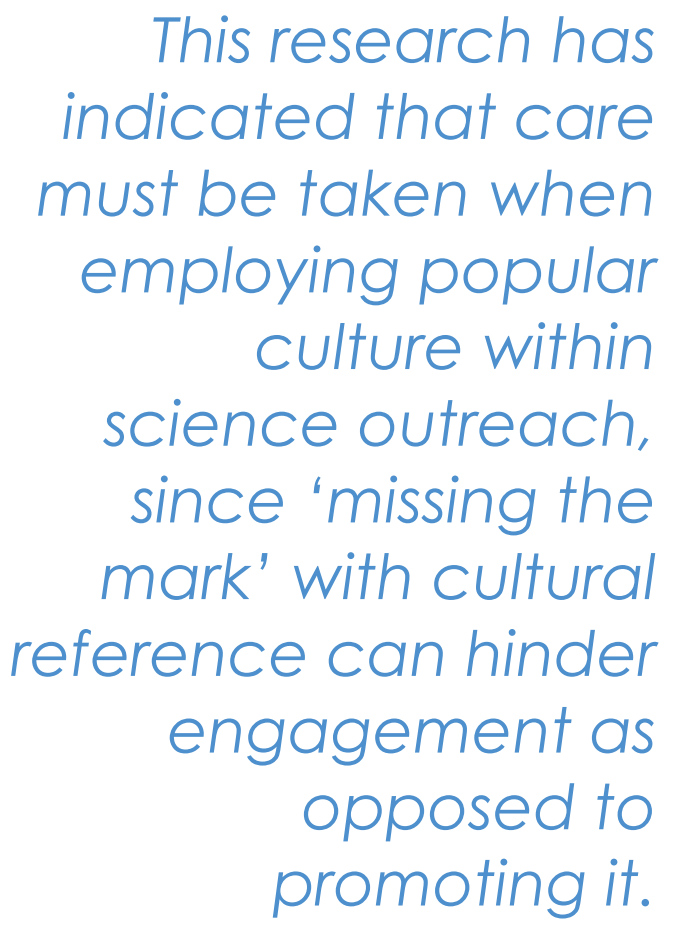

This research has indicated that care must be taken when culture within culture within science outreach, since 'missing the mark with cultura engagement as promoting it. 